\title{
Transmission Of Volatility Shocks Between The Equity And Foreign Exchange Markets In South Africa
}

Lumengo Bonga-Bonga, University of Johannesburg, South Africa

\begin{abstract}
The paper assesses the dynamic interaction between exchange rates and stock market volatility in South Africa by making use of the generalised impulse response function obtained from a bivariate VAR model. Volatility variables in the VAR system are obtained from a family of GARCH models based on criteria such as covariance stationarity and leverage effects. The findings of the paper show that foreign exchange conditional volatility responds positively to volatility shocks to the equity market. Nonetheless, the response of the equity market conditional volatility to volatility shocks to the foreign exchange market is short-lived and neutral for most of the time horizon periods. The paper attributes this finding mainly to the extent of foreign participation in emerging equity market in general and the South African equity market in particular.
\end{abstract}

Keywords: Stock Market Volatility; VAR Model; Volatility Shocks; South African Equity Market

\section{INTRODUCTION}

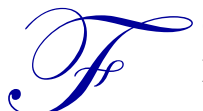

oreign investor participation in emerging markets such as South Africa has grown steadily over the past 10 years. The growing participation of international investors in emerging markets and the associated cross-border equity flows have led to an increase in the level of interdependency between stock prices and exchange rates (Kanas, 2000:447). From a portfolio point of view, the interaction between stock prices and exchange rates is important for the pricing of securities within and across markets, and for the trading and hedging strategies of investors (Mishra, Swain and Malhotra, 2007:344). Moreover, for international equity investors the total return from investing in a particular share or currency is the sum of the percentage change in the index and the percentage change in the currency. Thus, exchange rate movements contain useful information about the expected returns from investing in a foreign market (Aloui, 2007). On the other hand, changes in money demand, inflation and interest rates due to increases in stock prices influence exchange rate movements, providing another link between stock prices and exchange rates (Nieh and Lee, 2001).

Recent financial and currency crises have stimulated an interest in understanding the nature of the interaction of stock market and exchange rate volatilities. Volatility spillovers are a source of concern because they can propagate volatility shocks between the markets increasing the risk of a financial crisis. Understanding volatility co-movement and associated spillovers effects is therefore crucial to the management and prevention of financial crises. From a risk management point of view, understanding the interaction of exchange rate and stock price volatility is crucial given that exchange rate risk is one of the key risks facing modern corporations. Kanas (2000) argues that positive and significant volatility spillovers may increase the non-systemic residual international portfolio risk faced by international investors, reducing the gains from international diversification.

A few studies have examined the relationship between stock prices and exchange rates (see for example Phylatkis and Ravazzalo (2000), Ajayi and Mougouè (1996), Granger, Huang and Yang (2000) and Nieh and Lee (2001)). Such studies usually employ time series techniques such as Engle and Granger causality tests and Johansen co-integration techniques to examine the long-run and short-run dynamics between the variables. The results of such 
studies are very mixed. Others like Phylaktis and Ravazzolo (2000), Huzaimi and Liew (2004), Ajayi and Mougouè (1996) and Granger, Huang and Yang (2000) generally found evidence of a significant relationship. Contrary to these studies, Nieh and Lee (2001) found the variables to be unrelated. On the volatility relationship, the literature is even more scant. In addition, the few studies that are available mainly focus on developed countries (see for example Choi, Fang and Fu (2009), Yang and Doong (2004) and Kanas (2000) and Aloui (2007)) ignore trends in emerging markets. The poor development of financial markets in emerging markets and the low levels of liquidity have been cited as one of the reasons for the limitation. Nonetheless, Mishra, Swain and Malhotra (2007) explore the long-run relationship and volatility spillover between the Indian stock and foreign exchange markets.

In this study, we investigate the interactions between exchange rates and stock market volatility in South Africa by making use of a generalized impulse response function obtained from a VAR model, whereby a vector autoregressive model is constructed from conditional volatility of equity prices and the rand-dollar exchange rates obtained from different GARCH models. This paper is structured as follows: section 2 presents the literature review on the linkage between equity prices or returns and exchange rates, section 3 deals with the methodology used in the paper, section 4 presents and discusses the results of the paper and section 5 concludes the paper.

\section{THEORY AND LITERATURE REVIEW}

In explaining the link between stock prices and exchange rates, most studies appeal to the traditional models such as the macro-economic flow-oriented models and the portfolio balance theories such as the stockoriented theories. Aloui (2007) distinguishes between the macro-economic flow-oriented approach and the stockoriented approach. The traditional flow-oriented models are based on the idea that movements in exchange rates affect the current account balances or trade balances. Foreign exchange rate movements can affect international competitiveness of firms, trade balances and real income. According to Huzaimi and Liew (2004:3-4), the appreciation (or depreciation) of a local currency will decrease (or increase) indebtedness in terms of foreign currency denominated debts. In other words, the outstanding debts of local companies will be worth less (or more) and thus they will have to pay less (or more) in terms of the domestic currency. As a result, companies' cash flows will improve (or deteriorate). Importers will also benefit, as they will experience a decrease (or increase) in production costs leading to a gain (or loss) in revenues and price competitiveness. The net effect will be an increase (or decrease) in companies' net worth and stock prices. Exporters, on the other hand, will experience a loss (gain) in price competitiveness from currency appreciation (depreciation). Higher exports will lead to higher income and stock prices. The flow-oriented models suggest a relationship between stock prices and exchange rates, where causality runs from exchange rates to stock prices. However, the impact of currency appreciation (depreciation) on stock prices will depend on whether the stock market is dominated by exporters or importers, making this channel uncertain.

Capital flows and the trading in assets across borders is the focus of the portfolio approach. In the foreign exchange market, exchange rates are like any other commodity where the price is determined by market demand and supply forces. A booming stock market attracts capital inflows from foreigners seeking high returns, who sell the foreign currency in return for local currency. Capital inflows will thus lead to an appreciation of the exchange rate. Conversely, a stock market in decline will discourage capital inflows and thus lead to capital outflows, which will devalue the value of the domestic currency. The increase (or decrease) in stock prices will have additional effects by increasing (or decreasing) the wealth of domestic investors, increasing (or reducing) the demand for local currency pushing up (or down) the local interest rates. The higher (or lower) interest rates will encourage more capital inflows (outflows), resulting in a further appreciation (or depreciation) of the currency (Huzaimi and Liew, 2004:4). According to this approach, changes in stock prices lead changes in exchange rates, with causality running from stock prices to the foreign exchange market. The portfolio approach predicts a positive correlation between stock prices and exchange rates where higher stock prices lead to an appreciation in the currency.

Both the traditional approach and the portfolio approaches predict a positive volatility relationship. Exchange rate volatility creates cash flow uncertainty for local firms. This uncertainty will be reflected in increased stock price volatility as investors process information regarding expected stock returns. Likewise, volatile stock prices will impact on the exchange rates as the market return uncertainty for investors induces trading activity and capital outflows. 
Empirical tests on the relationship between stock prices and exchange rates produce mixed results. Some researchers argue that changes in stock prices lead changes in exchange rates (see Phylaktis and Ravazzolo, 2000), while others are of the view that exchange rates lead changes in stock prices (see Huzaimi and Liew, 2004). Phylaktis and Ravazzolo (2000:14) found evidence of a positive relationship between stock prices and exchange rates in the pacific basin. Results also showed that in Indonesia and Singapore the variables are linked through the flow approach. Granger, Huang and Yang (2000) found that the portfolio approach, where stock prices lead exchange rates, largely dominated the traditional approach in Asia during the Asian flu period. The feedback approach, where either market can take the lead, was also found to be important. ${ }^{1}$ Ajayi and Mougoue (1996) examine the relationship between stock prices and exchange rates for a group of industrialised countries by testing for cointegration in the variables. The results showed that stock prices and exchange rate in the major markets are integrated. Results of an error correction model showed that significant feedback relations exist between the two markets both in the short run and the long run. An increase in the aggregate stock price was found to have a negative short-run effect on domestic currency value, possibly because of inflation expectations generated by a booming stock market. In the long run the negative impact of a booming stock market on the exchange rate (appreciation in the currency) is consistent with the asset view of exchange rates. The authors argue that a booming stock market attracts investors, who buy the domestic currency, causing it to appreciate. On the other hand, currency depreciation has a sustained short-run and long-run negative impact on stock prices. The inflationary impact of currency depreciation and the unfavourable impact on imports may explain the observed negative impact of currency depreciation on stock prices. On the issue of causality, Huzaimi and Liew (2004:16) found evidence of bi-directional causality between exchange rates and stock prices in Malaysia. However, in Thailand they found evidence of unidirectional causality from exchange rates to stock prices.

Contrary to Phylaktis and Ravazzolo (2000), Huzaimi and Liew (2004, Ajayi and Mongue (1996), and Granger et al., (2000) Nieh and Lee (2001) found no significant relationship between the two variables. Their study employed Engle Granger and Johansen Cointegration techniques to examine the long-run relationship between the variables. Both approaches found no significant long-run relationship for all G7 countries, except the US where the Dow Jones Industrial Average and the Dollar Index were found to be moving together. The short-run analysis in the VECM shows that the financial variables in certain countries have only one-day predictive power.

Empirical research on the interaction between stock prices and exchange rates has traditionally focused on the first moments of the variables, ignoring trends in the second moments. In addition, the few studies that have modelled the second moments of exchange rates and stock prices have predominantly focused on developed countries, largely ignoring developments in developing countries (see for example Yang and Doong (2004), Aloui (2007) and Kanas (2000)). Yang and Doong (2004) investigate the interactions of price and volatility spillovers between the stock market and the foreign exchange market for the G-7 countries. A multivariate version of Nelson's (1991) EGARCH model was estimated. Their results indicated that there were significant price spillovers from the foreign exchange to the stock market for Canada and Japan. ${ }^{2}$

On the volatility spillovers generally, empirical evidence supports the existence of volatility spillovers from the stock market to the foreign exchange market, but not vice versa (see for example Yang and Doong (2004); Kanas (2000); Choi, Fang and Fu (2009); Aloui (2007)). In contrast, Dark, Raghavan and Kamepalli (2008) found evidence of volatility spillovers from the exchange rate to the stock market in Australian. Yang and Doong (2004)

\footnotetext{
${ }^{1}$ Their sample period was divided into three periods: the pre-1987 crash, the post-1987 crash and the Asian flu period. During the crisis period, there appeared to be little interaction between exchange rates and stock prices, except in the case of Singapore, where it was found that exchange rates lead stock prices. No interactions between exchange rates and stock prices were found in the other markets. Exchange rates were found to lead stock prices in Singapore again in the post-crisis period. Stock prices led exchange rates in Taiwan and Hong Kong during this period, providing support for the portfolio approach. In the Asian flu period, exchange rates were found to lead stock prices in South Korea, while stock prices led exchange rates in Hong Kong and Philippines. The rest of the markets (Singapore, Thailand, Malaysia, and Taiwan) displayed feedback patterns, with correlations going in either direction. No relationship between exchange rates and stock prices was found in Indonesia and Japan.

${ }^{2}$ Currency depreciation (or appreciation) often dragged down (up) stock prices. The results also found significant price spillovers from the stock market to the foreign exchange market for Canada, France, Germany, Italy, and the UK. In the short run an increase (or decrease) in stock prices often caused currency depreciation (or appreciation), while in the long run, an increase (decrease) in stock prices is associated with currency strength (weakness).
} 
found the existence of volatility spillovers from the stock market to foreign exchange market for most of the G7 countries. However, no volatility spillovers from the foreign exchange market to the stock markets were found. In terms of asymmetric spillover effects, negative innovations in the stock market had greater impacts on the conditional volatility of exchange rates than positive innovations; however, the effects did not apply to innovations in exchange rates on the stock markets.

Kanas (2000) examined volatility spillovers between the stock market and the foreign exchange market for six industrialised countries. The results showed evidence of volatility spillovers from stock returns to exchange rate changes for five of the six countries considered. However, no volatility spillover effects from exchange rate changes to stock returns were found for any on the countries. All stock return spillovers were found to be symmetric, meaning that the effect of bad stock market news on the exchange rate is the same as the effect of good news. Choi, Fang and Fu (2009) investigated the volatility spillover between the stock market and the foreign exchange market within the New Zealand (NZ) economy. The EGARCH model was used to examine the dynamic volatility relationship between the NZ stock market and the foreign exchange rate changes. Results indicate the presence of volatility spillovers from the stock market to the foreign exchange market. No volatility spillovers from exchange rates to stock prices were found. Evidence of leverage effects was found in both the stock market and the foreign exchange market.

Aloui (2007) adopted an empirical approach based on a multivariate EGARCH model to investigate the dynamic price and volatility spillovers between exchange rates and stock indexes for major European markets. The analysis covers the pre- and post-euro periods. The results indicate significant spillovers from the foreign exchange market to the stock market in both periods. There were also significant spillovers from stock prices to exchange rates in both periods. Overall, changes in stock prices were found to be significant informational signals to foreign exchange dealers, but the exchange rate does not appear to be as significant factor. Significant volatility spillovers from the stock market to exchange rates were found for most of the countries in both periods. Volatility spillovers from the exchange rate market to the stock market were found in the post-euro period for three out of the five countries; however, no volatility spillovers were found in the pre-euro period.

Few studies have focused on the linkage between stock market and exchange rate in the context of emerging markets and/or developing economies. Among studies on emerging economies is the work of Mishra, Swain and Malhotra (2007), who used the GARCH/EGARCH approach to examine volatility spillovers between stock and foreign exchange markets in India. Results suggested that in general both markets move together and that there is a long-run relationship between the two markets. They found evidence of bi-directional volatility spillover between the stock market and the foreign exchange market, except in the case of the stock indices such as S\&P CNX NIFTY and S\&P CNX 500. For both these markets unidirectional spillovers from the stock market to the foreign exchange market were found. Another study on an emerging market country is the work of Adjasi, Harvey and Agyapong (2008). Using the EGARCH approach they study the effect of the exchange rate volatility and volatility of other macro-economic variables (Inflation, trade deficit and treasury bill rates) on stock market volatility in Ghana. Exchange rates and stock price volatility were found to be negatively related, meaning that high exchange rate volatility leads to a decrease in stock market volatility. Their findings also showed that in addition to the volatility of exchange rates, stock market volatility is also influenced by the volatility of other macro-economic variables such as inflation and T-bill rates.

The methodological contribution of this study is that the VAR system used is constituted of conditional volatility variables obtained from different GARCH models based on criteria such as covariance stationarity and leverage effects.

\section{METHODOLOGY}

This paper employs the VAR model as suggested by Leachman and Francis (1996). With this methodology, the GARCH model is used to obtain estimates of the conditional variances of the return of equity index and the change in exchange rate. These estimates are then used to construct a VAR model. The obtained impulse response functions obtained from the VAR model will show how volatility shocks to one market influence the dynamic adjustment of volatility in the other market and the persistence of these spillover effects. It is important to note that 
the VAR approach employed in this study is suited to the purpose of this study, which aims at analysing the intertemporal dynamic properties of a particular data set.

The VAR model used in this study differs to the one proposed by Leachman and Francis (1996) in that the dynamic adjustment of volatility or spillover effects is interpreted from the generalised rather than the orthogonalised impulse response functions. It is important to note that contrary to orthogonalised impulse response, the generalised impulse response does not depend on the order of the variables included in a specific vector (Pesaran and Shin, 1998). Moreover, another contribution of this paper is that the conditional volatility of each market is modeled by taking into account the leverage effect and covariance stationarity conditions. The reason behind these conditions is that there is an a priori belief that stock returns depict asymmetric volatility in that stock return volatilities react differently to bad and good news; nonetheless, such asymmetric reaction in exchange rate volatility has no theoretical basis (Nelson, 1991).

With regards to the generalized impulse response function, Pesaran and Shin (1998) show that with a VAR model given as:

$$
X_{t}=\sum_{i=1}^{p} \Phi_{i} X_{t-i}+\psi W_{t}+\varepsilon_{t}, \quad t=1,2, \ldots, T
$$

where $X_{t}=\left(x_{1 t}, x_{2 t}\right)$, and in the case of this paper $x_{1 t}$ and $x_{2 t}$ represent the conditional volatilities for the equity and foreign exchange markets, respectively. $W_{t}$ is a vector of deterministic and/or exogenous variables. $\Phi_{i}$ and $\psi$ are coefficient matrices. It is assumed from Equation 1 that $E\left(\varepsilon_{t}\right)=0, E\left(\varepsilon_{t} \varepsilon_{t}^{\prime}\right)=\Sigma$ for all t, where $\Sigma$ is a covariance matrix.

The infinite moving average representation of Equation 1 is given as:

$$
X_{t}=\sum_{i=0}^{\infty} A_{i} \varepsilon_{t-i}+\sum_{i=0}^{\infty} G_{i} W_{t-i}, \quad+\varepsilon_{t}, \quad t=1,2, \ldots, T
$$

where $A_{i}=\Phi_{1} A_{i-1}+\Phi_{2} A_{i-2}+\ldots+\Phi_{p} A_{i-p} \quad$ and $\quad G_{i}=A_{i} \psi$

Given the history of the economy up to time $t-1$, denoted by the information set $\Omega_{t-1}$, the generalised impulse response function of $X_{t}$ at horizon $n$ is defined as:

$$
G I_{x}\left(n, \delta, \Omega_{t-1}\right)=E\left(X_{t+n} / \varepsilon_{t}=\delta, \Omega_{t-1}\right)-E\left(X_{t+n} / \Omega_{t-1}\right)=A_{n} \delta
$$

where $\delta$ is a hypothesised vector of shocks, which is essential to define the properties of the impulse response function. 


\section{DATA ANALYSIS AND EMPIRICAL RESULTS}

To determine the dynamics of volatility transmission between the equity and foreign exchange markets in South Africa, weekly data from 1 July 1995 to 31 October 2010 of the logarithm of All-share equity index and randdollar exchange rates were used. The sample periods correspond with the period after the liberalisation of the Johannesburg Stock Exchange, the main stock exchange in South Africa. Figure 1 shows the presence of volatility clustering in the first difference of the logarithms of the all-share equity index (d(EQT) and the rand-dollar exchange rates $(\mathrm{D}(\mathrm{EXCH})$ series. This outcome indicates that a class of GARCH models can be used to estimate conditional volatility for each of the two time series.
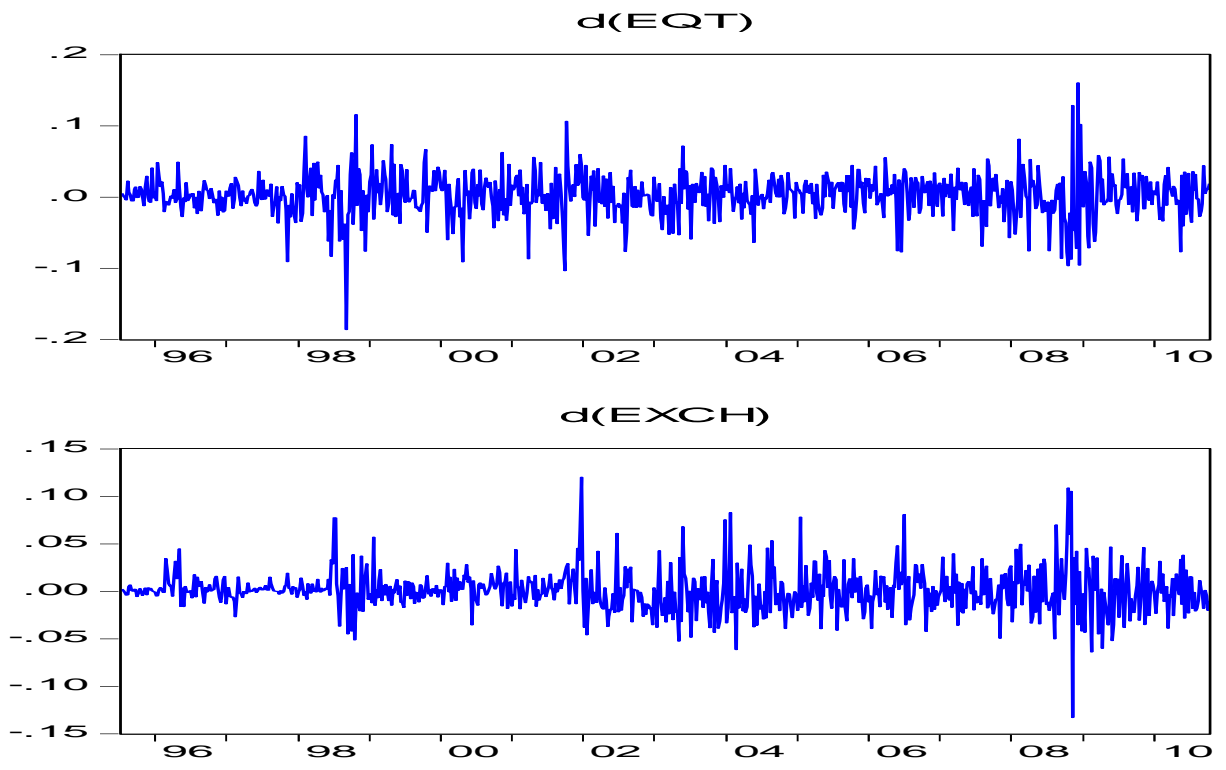

Figure 1: Time Series of d(EQT) and d(EXCH)

The first step of our model estimation, which consists of obtaining the conditional volatility of the two time series, necessitates a proper selection of the GARCH model. A number of empirical studies support the use of an $\operatorname{AR}(1)$-EGARCH $(1,1)$ process for modelling stock returns and testing the weak-form efficient market hypothesis in emerging stock markets (Abdmoulah, 2010; Shin, 2005; Salman, 2002; Zalewska-Mitura and Hall, 1999). The rationale for using $\mathrm{AR}(1)$ representation in modelling the mean process of equity returns and the change in exchange rate is based on weak-form efficiency and the random walk characteristics of the two variables (Fama, 1965). Nonetheless, the lag selection of the AR process is taken from the one that minimises the Schwarz Information Criteria (SIC). Table 1 presents the results of the SIC of the AR(1), AR(2) and AR(3) models for equity returns and the change in exchange rate. The paper limits the comparison to three lags, as it is proven that there is no evidence of long memory in the South African equity market (Jefferis and Thupayagale, 2008). The results of the SIC presented in Table 1 show that the mean process of $\mathrm{d}(\mathrm{EXCH})$ and $\mathrm{d}(\mathrm{EQT})$ is better represented by an $\mathrm{AR}(1)$ process.

Table 1: SIC Statistics for the AR(1), AR(2) and AR(3) Models of d(EQT) and d(exch)

\begin{tabular}{|lcc|}
\hline & d(EXCH) & d(EQT) \\
\hline AR(1) & -4.7765 & -4.1719 \\
AR(2) & -4.7732 & -4.1646 \\
AR(3) & -4.7635 & -4.155 \\
\hline
\end{tabular}

Note: the SIC statistics is minimized for AR(1) process in the case of the two variables. 
While it is theoretically plausible that conditional volatility of equity returns can be obtained from AR(1)$\operatorname{EGARCH}(1,1)$, there is no such evidence for conditional volatility of exchange rate, and this should be a matter of empirical analysis. Thus, Tables 2, 3 and 4 compare the results of the estimation of the volatility equation of the univariate $\mathrm{AR}(1)-\mathrm{GARCH}(1,1), \operatorname{AR}(1)-\mathrm{EGARCH}(1,1)$ and $\mathrm{AR}(1)-\mathrm{ARCH}(1)$ models for $\mathrm{d}(\mathrm{EXCH})$, respectively, in order to select the appropriate GARCH model for conditional volatility modelling based on the leverage effect and conditional stationarity hypothesis.

Table 2: Estimation of the Volatility Equation of the $\operatorname{AR}(1)-\operatorname{GARCH}(1,1)$ for $\mathrm{d}(\mathrm{EXCH})$

\begin{tabular}{|lc|}
\hline \multicolumn{1}{|c|}{ Parameter } & Coefficients \\
\hline$\omega_{0}$ & $0.00000588^{*}$ \\
$\beta_{1}$ & $0.1778^{*}$ \\
$\gamma_{1}$ & $0.8308^{*}$ \\
\hline
\end{tabular}

Note: The conditional volatility equation estimated in Table 2 is: $\sigma_{t}^{2}=\omega_{0}+\beta_{1} \varepsilon_{t-1}^{2}+\gamma_{1} \sigma_{t-1}^{2}$. * and ** mean significant at $1 \%$ and $5 \%$, respectively.

Table 3: Estimation of the Volatility Equation of the AR(1)-EGARCH (1,1) for d(EXCH)

\begin{tabular}{|lc|}
\hline Parameter & Coefficients \\
\hline$\omega 1$ & $-0.649^{*}$ \\
$\beta_{2}$ & $0.344^{*}$ \\
$\theta_{2}$ & 0.032 \\
$\gamma_{2}$ & $0.95^{*}$ \\
\hline
\end{tabular}

Note: Conditional volatility equation is: $\ln \left(\sigma_{t}^{2}\right)=\omega_{1}+\beta_{2} \frac{\varsigma_{t-1}}{\sqrt{\sigma_{t-1}^{2}}}+\theta 2\left|\frac{\varsigma_{t-1}}{\sqrt{\sigma_{t-1}^{2}}}\right|+\gamma_{2} \ln \sigma_{t-1}^{2}$.* and ** mean significant at $1 \%$ and $5 \%$, respectively.

Table 4: Estimation of the Volatility Equation of the AR(1)-ARCH (1,1) for d(EXCH)

\begin{tabular}{|lc|}
\hline Parameters & Coefficients \\
\hline$\omega_{0}$ & $0.0003^{*}$ \\
$\beta_{1}$ & $0.3504^{*}$ \\
\hline
\end{tabular}

Note: The conditional volatility equation estimated 4 is as: $\sigma_{t}^{2}=\omega_{0}+\beta_{1} \varepsilon_{t-1}^{2} . *$ and $* *$ mean significant at $1 \%$ and $5 \%$, respectively.

The results of the estimation of the EGARCH model of the change in exchange rate reported in Table 3 show that the coefficient $\theta_{2}$ is not statistically different from zero. This indicates that there is no asymmetric effect in the conditional volatility of the change in exchange rate series. Furthermore, the estimation of the AR(1)GARCH(1,1) equation reported in Table 2 shows that the sum of the coefficients $\beta_{1}$ and $\gamma_{1}$ is more than unity. This shows that the process is not covariance stationary and may not converge to a unique solution. Nonetheless, the results reported in Table 4 show that the conditional volatility of $\mathrm{d}(\mathrm{EXCH})$ can be represented better by an $\mathrm{ARCH}$ process, with the coefficient $\beta_{1}<1$ reflecting that the $\mathrm{ARCH}$ process is covariance stationary. These results indicate that conditional volatilities of equity returns and change in exchange rate can be estimated from AR(1)$\operatorname{EGARCH}(1,1)$ and $\mathrm{AR}(1)-\mathrm{ARCH}(1,1)$, respectively.

Having obtained the conditional volatilities of the foreign exchange market and the equity market in South Africa, VAREXCH and VARRET, respectively, Figure 2 presents their graphical representations. As in Figure 1, Figure 2 shows the high response of the two conditional volatilities to the emerging market currency crisis of 1998 and 2002 as well as the global financial crisis of 2008. This reality indicates that VAREXCH and VARRET are co- 
breaking and that there is a possibility that they are cointegrated. The information on whether the two series are cointegrated is very important in the light of the second step of the analysis, whereby an impulse response function is obtained from the constructed VAR model. Pesaran and Shin (1998) show that the generalised impulse response function obtained from a cointegrated VAR model should take into account the restrictions applied to the cointegrating vector.
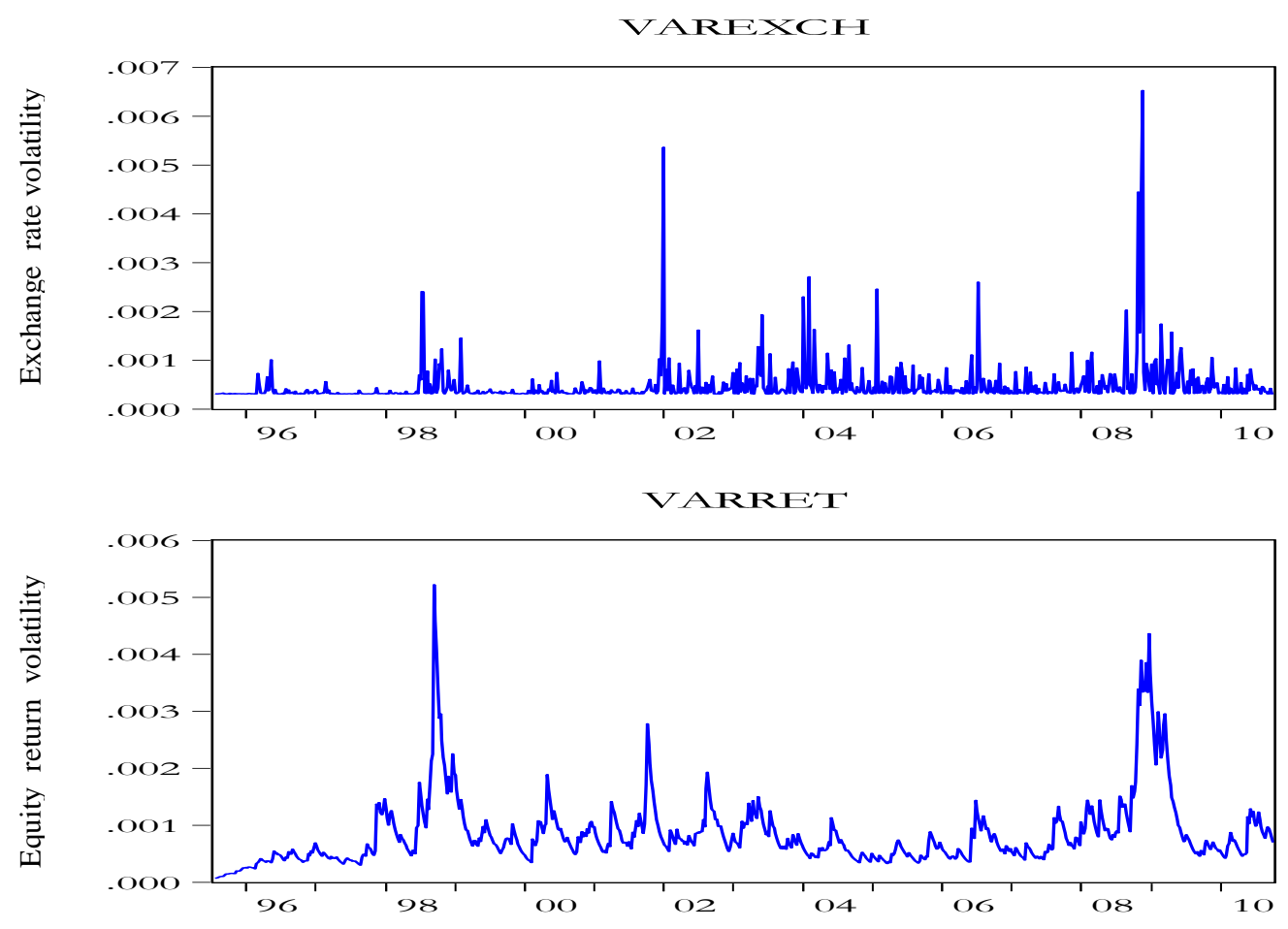

Figure 2: Conditional Volatilities of the Change in Rand-Dollar Exchange Rate and the Returns on the All-Share Equity Index

To test whether VAREXCH and VARRET are cointegrated, we first test the two series for unit root. The results of the Saikkonen and Lutkepohl (2002) unit root test with structural break reported in Table 5 show that the null hypothesis of unit root is rejected for the two series. This indicates that the two series are stationary and, thus, there is no need to proceed with the test of cointegration.

Table 5: Unit Root Test with Structural Break for VAREXCH and VARRET

\begin{tabular}{|lcccc|}
\hline & & \multicolumn{3}{c|}{ Critical values } \\
\cline { 3 - 5 } \multicolumn{1}{c|}{ Variables } & Test Statistics & $\mathbf{1 \%}$ & $\mathbf{5 \%}$ & $\mathbf{1 0 \%}$ \\
\hline VAREXCH & -11.01165 & -3.48 & -2.88 & -2.57 \\
VARRET & -5.0947 & -3.48 & -2.88 & -2.57 \\
\hline
\end{tabular}

Before obtaining the generalised impulse response function from the bivariate VAR, we undertake the test of the stability of the VAR system. The stability test of the VAR system is important, as it informs whether after a given shock to the system it converges to a unique solution or equilibrium. The autoregressive (AR) root lag structure, reported in Table 6, indicates that no roots lies outside the unit circle; hence the VAR satisfies the stability condition.

Table 6: Stability Condition of the VAR Process, Variables: VAREXCH, VARRET

\begin{tabular}{|lc|}
\hline \multicolumn{1}{|c|}{ Root } & Modulus \\
\hline 0.94068 & 0.94068 \\
0.271403 & 0.271403 \\
\hline
\end{tabular}

Note: No root lies outside the unit circle. VAR satisfies the stability condition 
It is important to note that the Schwart Information Criteria (SIC) has suggested the VAR model with lag one. Figure 3 displays the response of the conditional volatility of the change in rand-dollar exchange rate to one standard deviation volatility shocks to equity market returns, and Figure 4 displays the response of the conditional volatility of the equity market returns to one-standard deviation volatility shocks to change in rand-dollar exchange rate. The short time horizon of 26 weeks is considered appropriate for an assessment of the effect of financial shocks, given that the financial markets in emerging markets are dominated by investors with short trading horizons who react quickly to financial shocks (De Long et al., 1990).

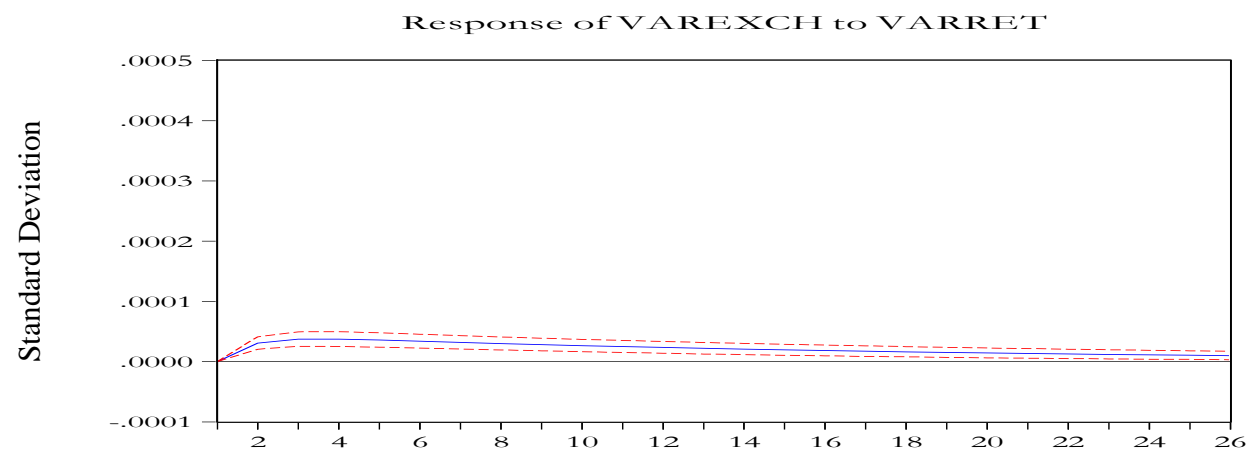

Figure 3: Response of VAREXCH to One Standard Deviation Shock to VARRET

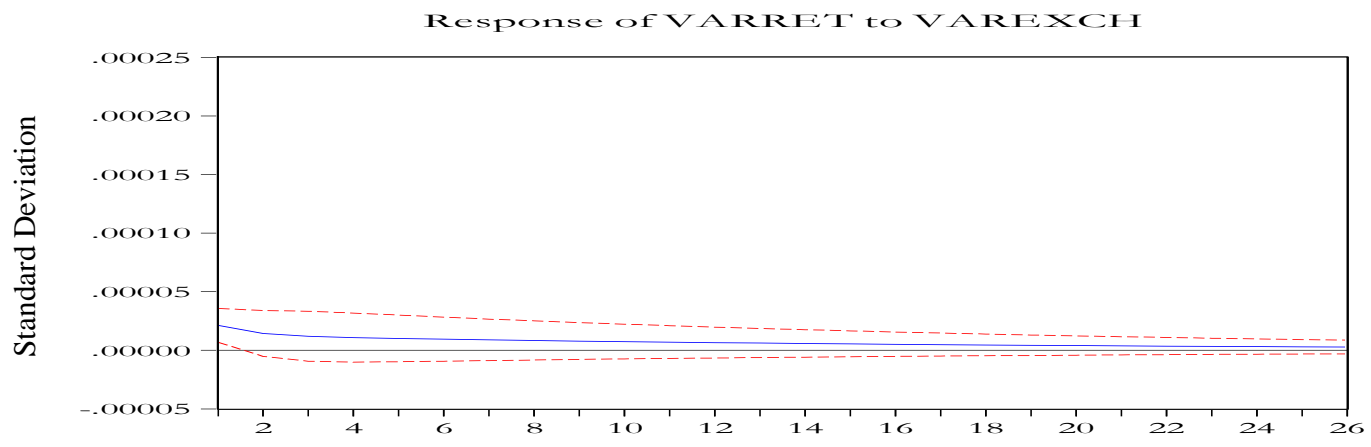

Figure 4: Response of VARRET to One Standard Deviation Shock to VAREXCH

The results in Figure 3 show that VAREXCH responds positively to shocks to VARRET and the effect is persistent and statistically significant for close to 22 weeks. The response of VARRET to shocks to VAREXCH, displayed in Figure 4, is short-lived and not statistically significant for most of the time horizon. The positive response of VAREXCH to shocks to VARRET indicates that volatility shocks to the equity market spill over to the rand-dollar foreign exchange market. The reason behind this finding has likely to do with the structure and the composition of emerging equity markets in general, and of the equity market in South African in particular. In fact, equity markets in emerging markets depend to a greater extent on foreign participation. High volatility in the equity markets, which signals an increasing degree of market risk, leads to the selling spree of emerging market assets by foreign market participants in order to relocate funds to more stable equity markets. This phenomenon leads to massive capital outflow and, thus, volatility in the foreign exchange market. The transmission of volatility from the equity market to foreign exchange market, and the resulting capital flow, indicates the disruptive effect of portfolio investment on the emerging markets' balance of payments and shows that it is the cause of volatile currency in these markets. It is in this context that a number of emerging market economies have adopted exchange control policy to mitigate the disruptive effects of capital flow on the balance of payment and currency.

On the importance of foreign participation in the South African equity market, It is important to note that foreign trading volume on the Johannesburg Securities Exchange (JSE), the sole licenced stock exchange in South Africa, has increased seven folds from 1996 to 2007 (JSE, 2008), indicating the importance of foreign participation in the JSE. 
While a number of authors find a causal link between foreign exchange markets and equity markets (Abdalla and Murinde, 1997), this paper shows that volatility transmission from the rand-dollar foreign exchange market to equity market is short-lived for a number of reasons. Firstly, volatility in emerging equity markets often emanates from instability in developed markets rather than from internal factors or markets. Thus, volatility shocks to the rand-dollar foreign exchange market may not necessary transmit to the equity market. Secondly, rand-dollar exchange rate risk may not necessary increase the risk of the equity market in emerging markets, as most foreign investors prefer to hedge against exchange rate risk before investing in emerging equity markets.

\section{CONCLUSION}

This paper attempted to assess the dynamics of volatility transmission between the equity market and the rand-dollar foreign exchange market. Use his made of the generalised impulse response function obtained from the VAR model to analyse the impact of volatility shocks emanating from one market on another market. The findings of the paper show that foreign exchange conditional volatility responds positively to volatility shocks to the equity market. Nonetheless, the response of the equity market conditional volatility to volatility shocks to the foreign exchange market is short-lived and neutral for most of the time horizon periods. The paper attributes this finding mainly to the extent of foreign participation in emerging equity market in general and the South African equity market in particular, whereby foreign investors often unwind their positions in the local equity market when volatility pressure increases. This action leads to high capital outflow and, thus, transmission of volatility from the equity to foreign exchange market. The paper indicates that it is indeed such transmission of volatility from the equity market to the foreign exchange market, through capital outflow, that has led a number of emerging market economies to adopt exchange control policies.

\section{AUTHOR INFORMATION}

Lumengo Bonga-Bonga, University of Johannesburg, Department of Economics and Econometrics, University of Johannesburg, Auckland Park 2006, Johannesburg, South Africa. E-mail: lbonga@uj.ac.za

\section{REFERENCES}

1. Abdalla, S.A. and Murinde, V. (1997). Exchange Rate and Stock Price Interactions in Emerging Financial Markets: Evidence on India, Korea, Pakistan and the Philippines. Applied Financial Economics, 7(1) 2535 .

2. Aloui, C. (2007). Price volatility spillovers between exchange rates and stock indexes for the pre and post euro period. Quantitative Finance, 7(6) 669-685.

3. Ajayi, R. A and Mougoue, M. (1996), 'On The Dynamic Relation Between Stock Prices and Exchange Rates', The Journal of Financial Research, XIX(2):193-207.

4. Choi, D.F.S., Fang, V. and Fu, T.Y. (2009). Volatility Spillovers between New Zealand Stock Market Returns and Exchange Rate Changes before and after the 1997 Asian Financial Crisis. Asian Journal of Finance \& Accounting, 1(2): 107-117.

5. Dark, J., Raghavan, M. and Kampellli, A. (2008). Return and Volatility Spillover between the Foreign Exchange Market and the Australian All Ordinaries Index. Journal of Applied Finance, 14(1) 41-48.

6. De Long, J.B, Shleifer,A., Summers, L.H. and Waldmann, R.J. (1990). Noise Trader Risk in Financial Markets. Journal of Political Economy, 98 703-738.

7. Granger, C.W.J., Huang, B. and Yang, C. (2000). A Bivariate Causality between stock prices and exchange rates: evidence from recent Asian flu. The Quarterly Review of Economics and Finance, 40, 337-354.

8. Huzaimi, H. and Liew, V.K. 2004. Causal relationships between exchange rate and stock prices in Malaysia and Thailand during the 1997 currency crisis turmoil. Available from: http://129.3.20.41/eps/if/papers/0405/0405015.pdf (Accessed 18 November 2010).

9. Jefferis, K. and Thupayagale, P. (2008). Long Memory In Southern African Stock Markets. South African Journal of Economics. 76(3): 384-398

10. Kanas, A. (2000). Volatility Spillovers Between Stock Returns and Exchange Rate Changes: International Evidence. Journal of Business Finance \& Accounting, 27(3) \& (4):448-467. 
11. Mihra, A.K., Swain, N. and Malhortra, D.K. (2007). Volatility Spillovers between Stock and Foreign exchange Markets: Indian Evidence. International Journal of Business, 12(3): 344-359.

12. Nelson, D.B. (1991). Conditional Heteroskedasticity in Asset Returns: A New Approach. Econometrica, 59(2): 347-370.

13. Pesaran, M.H. and Shin, Y. (1998). Generalised Impulse Response analysis in linear multivariate models. Economics Letters, 58: 17-29.

14. Phillips, P. and Perron, P. (1988). Testing for a Unit Root in Time Series Regression. Biometrica 75(2): 335-346.

15. Phylaktis, K and Ravazzolo, F., 2000. Stock Prices and Exchange rate dynamics. Available from: http://www.cass.city.ac.uk/emg/workingpapers/stock_prices_and_exchange.pdf (Accessed January 2012).

16. Saikkonen, P. and Lütkepohl, H. (2002). Testing for a unit root in a time series with a level shift at unknown time. Econometric Theory 18: 313-348.

17. Yang, S. and Doong, S. (2004). Price and Volatility Spillovers between stock prices and Exchange rates: Empirical evidence from the G-7 countries. International Journal of Business and Economics, 3(2):139153. 
NOTES 